\title{
Dynamic Simulation of a One DOF Radial Active Magnetic Bearing Using SIMULINK and AMESim Co-simulation
}

\author{
Abdollah Ebadi and Mahdi Aliyari Sh
}

\begin{abstract}
Because of their unique capabilities Magnetic Bearings are increasingly being used in different applications in various industries. MBs are divided in to three main type: 1) Active MB 2) Passive MB 3) Hybrid MB. Due to its adjustability active MBs are becoming common in overcoming classical rotor-bearing problems and help engineers reach new boundaries in system efficiency. The most important issue in designing an active $\mathrm{MB}$ is its control system which requires novel techniques to implement. To this end and because of the complicated nature of designing and verifying the functional correctness of the overall system, new co-simulation approaches are considered. In this paper a One-Axis (One-DOF) magnetic bearing co-simulation model using LMS Imagine AMESim and SIMULINK is proposed to show the capabilities of system modelling an AMB via AMESim software as a mechatronics system design software. The electromagnets of the magnetic bearing system is dealt as a magnetic actuator in AMESim while the rotor is modeled as a simple mass. Linear SISO controllers are designed using SIMULINK and a co-simulation interface is implemented to simulate the overall system
\end{abstract}

Index Terms-Active magnetic bearing, co-simulation, modelling, AMESim software, simulink.

\section{INTRODUCTION}

Recently Active Magnetic Bearings are widely used in the industrial applications because of the advantage of controlling, damping vibrations and obtaining a well-defined dynamic behavior. Furthermore, because of the omission of bearing fluids the overall system complexity is reduced. But the main attraction of active magnetic bearings is the fact that theoretically AMBs help eliminate mechanical friction due to the use of magnetic levitation and as a result very high rotating speeds is achievable in rotary machines. The design of AMB systems as a smart mechatronic product requires the knowledge of different disciplines including rotor dynamics, electromagnetism, power electronics, computer engineering and control theory. As a result to this fact new designing methods such as the use of modelling and simulation software like ADAMS and ANSYS in conjunction to SIMULINK [1], [2] are being used to simplify the design process. In this paper at first the electromechanical equations of a one DOF differential magnetic bearing is derived. Afterwards the magnetic and mechanical subsystems are modeled in AMESim software using its electromechanical and mechanical libraries. During this phase static calculation and design of the electromagnets are taken out to achieve the

Manuscript received September 25, 2014; revised July 27, 2015

The authors are with the Department of Mechatronics, K.N. Toosi University of Technology, Tehran, Iran (e-mail: Ebadi@ee.kntu.ac.ir). desired magnetic specifications. AMEsim is a bond graph based modelling software used in the industry to model mechatronics systems. Next based on the linearized equations derived from the first phase, two linear controllers are designed and verified using SIMULINK. After the correctness of the controllers is verified and the system specifications are meeting, the overall virtual prototype system is assembled using a co-simulation interface between AMESim and SIMULINK. At the end the simulation results are presented. This strategy could be extended to a 5 DOF decoupled magnetic bearing system and the outcome of this strategy is that we can repeatedly change the electromechanical and control specifications in this virtual prototype system, so as to remedy defects of traditional simulation technology and improve design efficiency of magnetic suspended rotor system.

\section{MATHEMATICAL MODEL OF A ONE DOF DiFFERENTIAL MAGNETIC SUSPENSION SYSTEM}

Fig. 1 [3] shows the overall structure of a one DOF magnetic bearing system. In the presented closed loop the sensor detects the amount of displacement of the rotor and the designed controller outputs a control signal to the power amplifier which in turn generates the required current to produce the regulating force in the electromagnet. Fig. 2 [4] shows a 2 pole electromagnet used to suspend and I shaped core. The $\mathrm{C}$-core has a width of $\mathrm{w}$ with a slack length $\mathrm{l}$. The main flux path is shown by the dotted line in the figure and the length of the flux path within the C-core is defined by $l_{1}$ and $l_{2}$. The flux path in the I core is stated by $l_{3}$. The air gap is $\mathrm{g}$ at its nominal position and the displacement $x$ is measured as a deviation from this position. Using the magnetic circuit concepts and assuming the deviation is small with respect to the nominal gap and that the magnetizing characteristic curve is linear, the nonlinear force equation 1) is derived. Since the AMB structure is a differential structure thus the total amount of force applied to the rotor in an axis is $F_{m 1}-F_{m 2}$ the current passing through the coils are $I_{b}-i_{c}$ and $I_{b}+i_{c}$ where $I_{b}$ is the equilibrium points current, substituting these values in equation 1) the linear equation 2) is produced [4].

$$
\begin{gathered}
F_{m}=\frac{L_{0}}{g} \frac{i^{2}}{2}+\frac{L_{0} i^{2}}{g^{2}} x \\
\left\{\begin{array}{c}
F_{m 1}-F_{m 2}=k_{i} i_{c}+k_{x} x \\
k_{i}=2 L_{0}\left(\frac{I_{b}}{g}\right) \\
k_{x}=2 L_{0}\left(\frac{I_{b}}{g}\right)^{2}
\end{array}\right.
\end{gathered}
$$


where:

$$
\begin{gathered}
L_{0}=\frac{N^{2} \mu_{0} w l}{2 g} \\
L_{0}=\text { Nominal Inductance } \\
\mu_{0}=\text { Magnetic Permeability of air } \\
N=\text { number of coil turns }
\end{gathered}
$$

In the above equations $K_{i}$ is the Force/Current factor and $K_{x}$ is known as the force/displacement factor which contributes to the unbalance pull force of a magnet attracting another core. This term is main reason for which an electromagnet attracting a core is inherently unstable. Equation (2) is valid for small amounts of displacement of the rotor and with the increase of distance from the equilibrium point the precision of (2) decreases.

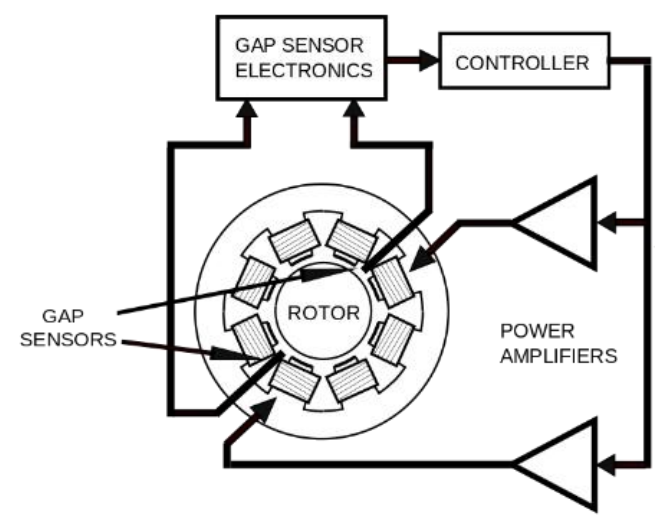

Fig. 1. General structure of an AMB [3].

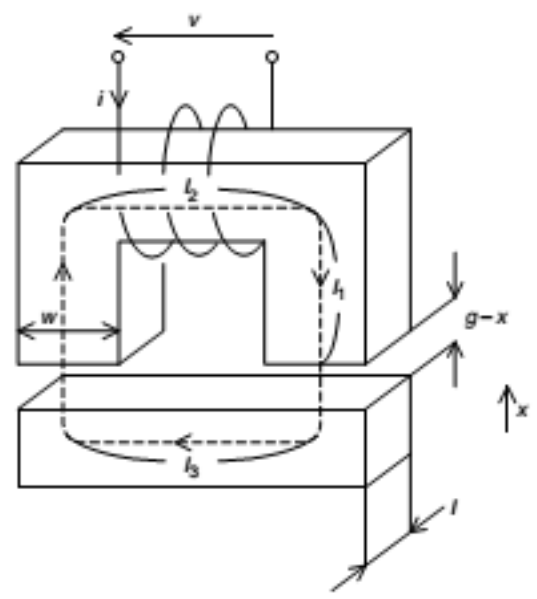

Fig. 2. Flux path of a C - Core magnet [4].

Using Newton's second law and the Laplace transformation we could derive the overall system transfer function for dynamic analysis. Equation (3) shows the output of the system in the Laplace domain.

$$
x(s)=K_{i} / m s^{2}-k_{x} \times i(s)_{c}-m G / m s^{2}-k_{x}
$$

In (3) the second term is the effect of gravitational force on the rotor which could be considered as a disturbance input when analyzing the equation. Fig. 3 shows the block diagram of the magnetic suspension system

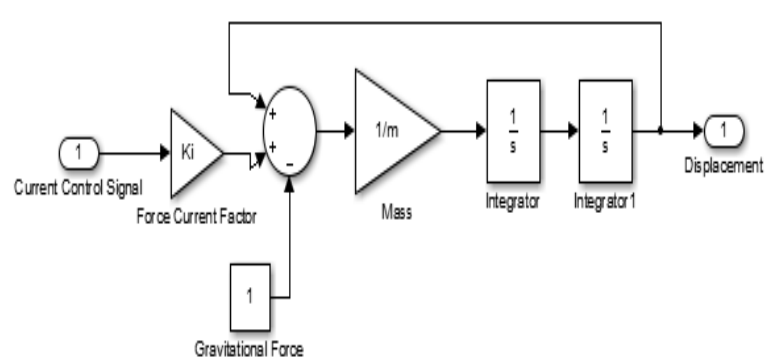

Fig. 3. Block Diagram of magnetic suspension system.

\section{ElECtRomechaniCAL MODEL OF A ONE DOF DifFERENTIAL MAGNETIC SUSPENSION SYSTEM IN AMESIM SOFTWARE}

LMS Imagine.Lab AMESim is an integrated platform for the design, simulation and virtual prototyping of mechatronic products [5]. This package offers extensive support for various libraries which help mechatronic engineers accurately predict the multidisciplinary performance of intelligent systems. AMESim is a bond graph based software its support for electric, magnetic and mechanical libraries make it an ideal platform for the modelling the electromagnetic actuation system of an AMB [6]. In addition AMESim supports software interface with other state of the art simulating software like SIMULINK and ADAMS. Fig. 4 shows a 2 pole electromagnet modeled using AMESim's electromechanical, Electric and mechanical libraries. Generally AMBs are controlled either using current control schemes or voltage control schemes. In the voltage control scheme, voltage of the electric circuit is considered as input and the current of the circuit flowing through the coil contributes to the overall system dynamics as a system state. This result comes from the fact that the coil introduces an inductance to the electrical circuit which in turn resists any sudden change in the current hence any fast current change in the circuit can only be achieved by a suitably high internal amplifier voltage.

If the amplifier is designed so that its response if very much faster than the magnetic and mechanical domains of the system then ideally speaking we could control the AMB using current control schemes which results in the usage of conventional linear controllers. To this end in the above figure an ideal current source is used as the input to the coil. The magnetic circuit consists of a coil to produce the required magneto motive force while magnetic elements are used to model the 2 pole core of the electromagnet. Finally an air gap element and a mechanical coupling element are used to transfer the magnetic force produced to the mechanical system. The parameters of Table I are used to design the electromagnet in order to meet the required design specifications. Using the values stated in Table I and considering the equilibrium operating point of the electromagnet as $(5 \mathrm{~mm}, 2 \mathrm{~A})$ the values of Table II are derived for the different air gaps in electromagnet. The reason the calculated values differ from the values AMESim provides is that AMESim calculates using its nonlinear model but the hand calculated values are based on the linear model we derived before. But Table II shows that the electromagnet model sketched in AMESim is correct and the force values are in the expected range. Fig. 5 shows the complete model of a one DOF AMB actuation system in 
AMESim. In this Fig. 2, subsystems consisting of the electromagnet model presented previously are used to insert the regulating force calculated by equation 2 to the mass rotor. The displacement of the rotor is sensed by the 2 displacement sensors, since AMESim is a bond graph based software the values are accompanied by a sign which refers to the value's direction of flow.

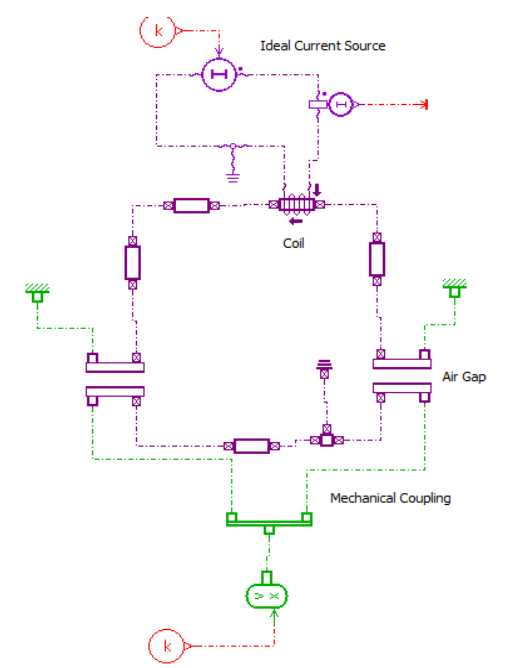

Fig. 4. 2 pole electromagnet model in AMESim.

Thus the absolute value for the displacement is detected and feedback to the control unit. AMESim and SIMULINK could be interfaced and integrated in two ways: 1) Model integration simulation 2) using Co-simulation.

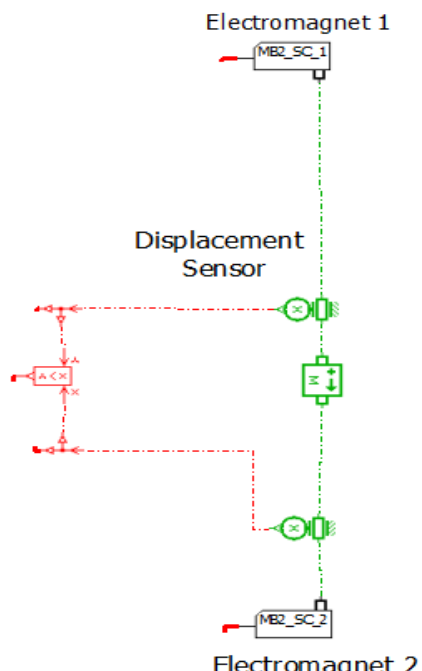

Fig. 5. Complete model of a differential one DOF magnetic actuation system in AMESim.

In the first approach a $\mathrm{C}$ file is generated by AMESim which could be imported in to a SIMULINK model by the usage of an S-function block and MATLAB's solver is used to solve the equations. In the second approach each software uses its own solver to derive the results of the subsystem modelled in its environment and the results are passed to the other software in predefined intervals. The second approach is used in this paper.

\section{CONTROLler DESIGN AND SimUlation IN SimUlinK ENVIRONMENT}

In this section two PD and PID control units are designed and simulated in the SIMULINK environment. Drawing the root locus of the open loop system for $\mathrm{Ki}$ and $\mathrm{Kx}$ parameters calculated using the values of Table I reveals that the open loop system is unstable. The transfer function of the system when using PD and PID compensators are calculated in equation (4) and (5) respectively. As can been seen the system is unstable as was expected and a controller is needed to stabilize the system. After designing the PD and PID controllers and calculating the required gains (Table III) the simulation results for the regulating effect of the PD and PID compensators performed in the SIMULINK environment is shown in Fig. 6. Because the closed loop system using a PD controller is of type 0 then the system will experience a steady state error due to the presence of the weight force as a disturbance. But with the addition of an integrator in the PID controlled system the type of the system is increased and thus the effect of weight modeled as a disturbance force in the system will disappear after the transient response. The results show that the both systems become stable with the help of the compensators. Next to verify the correctness of the model built in AMESim we will implement the controllers in AMESim and simulate the overall system.

TABLE I: DESIGN PARAMETERS FOR ELECTROMAGNETS
\begin{tabular}{|c|c|c|}
\hline$g$ & Nominal air gap & $5[\mathrm{~mm}]$ \\
\hline$N$ & Coil turns & $500[\mathrm{turns}]$ \\
\hline$w$ & Core width & $1[\mathrm{~cm}]$ \\
\hline$l$ & Slack length & $1[\mathrm{~cm}]$ \\
\hline$l 1$ & Pole lenght & $1[\mathrm{~cm}]$ \\
\hline$l 2$ & Core length & $4[\mathrm{~cm}]$ \\
\hline$l 3$ & $I$ Core length & $4[\mathrm{~cm}]$ \\
\hline$m$ & Rotor Mass & $0.1[\mathrm{~kg}]$ \\
\hline$I b$ & Bias Current & $2[\mathrm{~A}]$ \\
\hline
\end{tabular}

TABLE II: ForCE PRODUCED By ElECTROMAGNETS

\begin{tabular}{|c|c|c|c|}
\hline $\begin{array}{c}\text { Airgap } \\
\text { Length } \\
{[\mathrm{mm}]}\end{array}$ & 5 & 6 & 4 \\
\hline $\begin{array}{c}\text { AMESim } \\
\text { Force } \\
\text { Calculated } \\
{[\mathrm{N}]}\end{array}$ & 1.05523 & 0.753872 & 1.58123 \\
\hline $\begin{array}{c}\text { Calculated } \\
\text { by equation } \\
(1)-[\mathrm{N}]\end{array}$ & 1.25664 & 0.753984 & 1.759296 \\
\hline
\end{tabular}

\section{CONTROller Design AND SimUlation In AMESim ENVIRONMENT}

AMESim software provides the user with a "Signal and Control" library to be able to implement control systems for the designed mechatronic systems. In this section the PD and PID controllers are implemented in AMESim using its provided blocks and are connected to the AMB model to verify the correctness of the design.

TABLE III: COMPENSATOR GAINS CALCULATED

\begin{tabular}{|c|c|c|c|}
\hline $\begin{array}{c}\text { Controller } \\
\text { Type }\end{array}$ & $\begin{array}{c}\text { Proportional } \\
\text { Gain }\end{array}$ & $\begin{array}{c}\text { Derivative } \\
\text { Gain }\end{array}$ & Integral Gain \\
\hline PID & 1540 & 8 & 7500 \\
\hline PD & 1500 & 8 & ---- \\
\hline
\end{tabular}

Fig. 7 shows the schematic of the system implemented in AMESim and Fig. 8 shows the result of the output of the displacement sensor for both the PD and PID systems. It is 
apparent that the results match with the outcome from the previous section and thus the correctness of the modelling in both SIMULINK and AMESim is verified.

\section{Co-Simulation SETUP AND SimUlation}

With the correctness of the controller and model both verified in SIMULINK and AMESim in this section the interface between SIMULINK and AMESim is setup and a co-simulation operation is performed. AMESim provides a block which the user can use in order to connect its mechatronic design in AMESim to the control system implemented in SIMULINK. Fig. 9 shows the system assembly in AMESim environment. A block named "Simulink Cosim Control" is used in the presented model as an interface between AMESim software and SIMULINK.

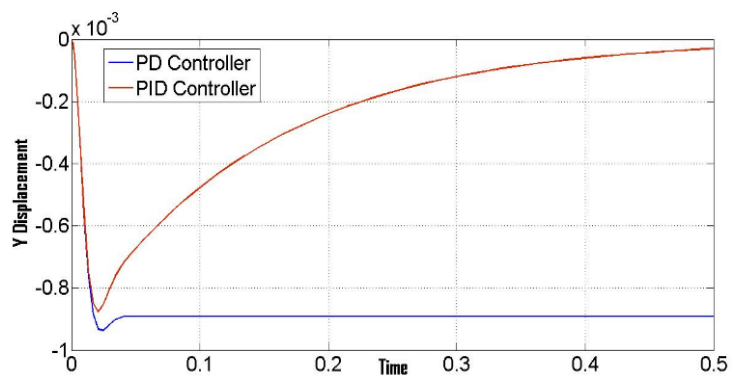

Fig. 6. Simulation results in SIMULINK (Red line shows PID results - Blue line shows PD results).

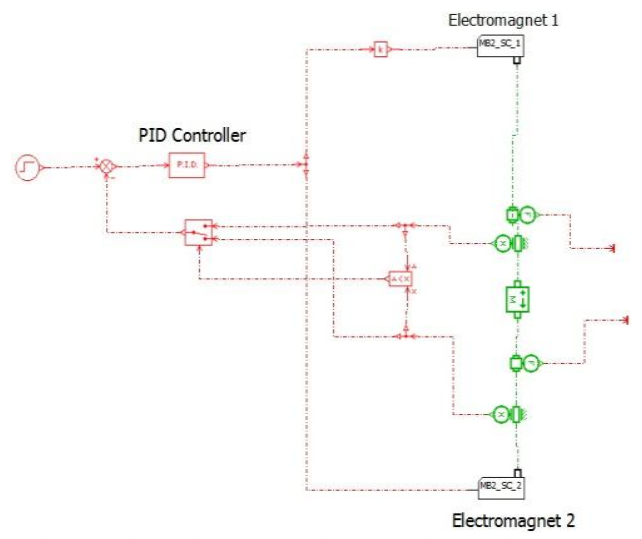

Fig. 7. Closed loop AMB in AMESim environment.

$$
\begin{gathered}
T C L_{P D} \stackrel{\text { def }}{=} \frac{37689+201.056 s}{s^{2}+201.056 s+27694.9} \\
T C L_{P I D} \stackrel{\text { def }}{=} \frac{20.1056 s^{2}+3872.023 s+18849}{0.1 s^{3}+20.1056 s^{2}+2866.712 s+18849}
\end{gathered}
$$

Fig. 10 shows the system assembly in SIMULINK for co-simulation with AMESim. In This model AMESim uses its own solver to obtain the results of the system states modeled in its environment, at predefined intervals output from AMESim which is the position of the rotor is sent to SIMULINK and this software uses its own solver to obtain the required control signal to regulate the rotor and sends the control command to AMESim which updates the model system states at this point. Fig. 11 shows the result of regulation of the co-simulation model.

\section{ANALYSIS OF SiMULATION RESUlTS}

In this paper 3 different types of simulations have been performed: 1- Simulation in SIMULINK environment 2Simulation in AMESim Environment 3- Co-Simulation using SIMULINK and AMESim. With comparing Fig. 6 and Fig. 8 and Fig. 11 it is apparent that results in all three match each other. But the question is how do they differ and which is the most accurate? The least accurate is the SIMULINK simulation since it is based on the assumptions which the designer makes for deriving a mathematical model for his/her design.

If the simulation parameters in both SIMULINK and AMESim are selected correctly then since two accurate solvers are used to simulate the controller and physical system then the co-simulation technique produces the most accurate results. Another important parameter to set when using simulation techniques is the solvers accuracy and step size, in order to achieve comparable results the step size in all of the environments is set to 0.0001 .

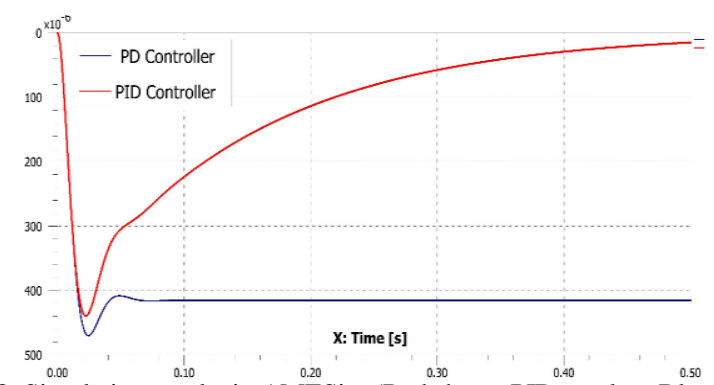

Fig. 8. Simulation results in AMESim (Red shows PID results - Blue shows $\mathrm{PD}$ results).

After running the simulation when looking at the step response of the three systems which are shown in Fig. 8 and 11 a slight break in the PID curve which is not available in Fig. 6 is apparent. This is because of the more detailed model which is at hand when using AMESim to model the physical structure of AMB. Comparing the results of Fig. 8 and Fig. 11 shows that the curves are alike, but if the controller setting becomes more complex the co-simulation setup will be preferable.

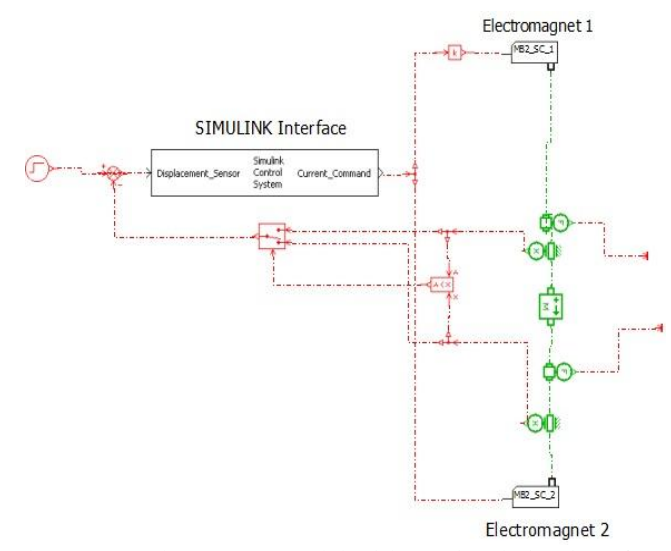

Fig. 9. Complete AMB model with co-simulation interface.

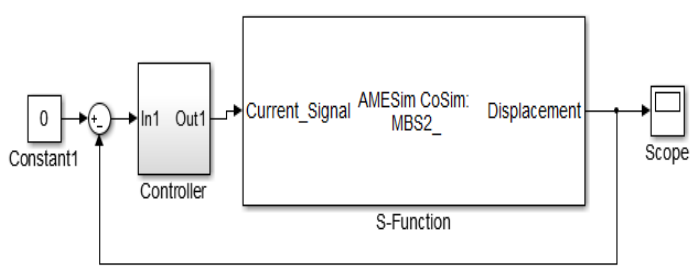

Fig. 10. SIMULINK assembly for AMB co-simulation.

All of the simulations show that the system is working 
correctly, when the PD controller is used the rotor falls to a distance from its initial position but still the rotor is suspended in air. This shows the steady state error that was expected by analyzing the transfer function of the system. When considering the PID controller the system converges to its nominal position after a transient response.

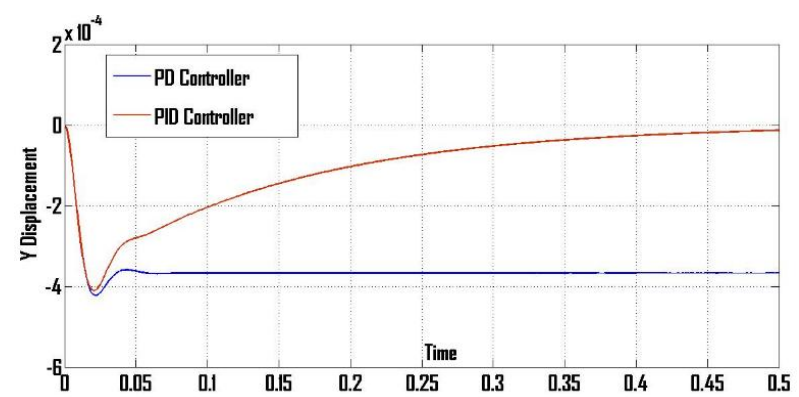

Fig. 11. Co-simulation results (Red shows PID results - Blue shows PD results).

\section{CONCLUSIONS}

This paper introduced a co-simulation model of AMESim and SIMULINK for a one DOF AMB system. First the mathematical equations where derived and using them the system controllers where designed in SIMULINK while the system's magnetic actuator and mass where modeled in AMESim.

A simulation was performed in SIMULINK with the use of the mathematical equations derived, a second simulation was performed in AMESim with the use of its control library and a final simulation was taken out interfacing SIMULINK and AMESim using their co-simulation interface. The results where all acceptable and they show how accurate a co-simulation system could work and that using this method. The concept performed in this paper could be extended to a multi DOF decoupled AMB system with SISO controllers.

\section{REFERENCES}

[1] J. G. Zhang et al., "Co-simulation of magnetic suspended rotor system research and application," in Proc. the 2009 IEEE int. Conf. on Mechatronics and Automation, 2009, pp. 1711-1715.

[2] D. L. Zhu et al., "Research on co-simulation using ADAMS and MATLAB for active vibration isolation system," in Proc. Int Conference on Intelligent Computation Technology and Automation, 2010, pp. 1126-1129.

[3] Magnetic_bearing. [Online]. http://en.wikipedia.org/wiki/Magnetic_bearing

Available:

[4] A. Chiba, T. Fukao, O. Ichikawa, M. Oshima, M.Takemoto, and D. G. Dorrell, Magnetic Bearings and Bearingless Drives, Elsevier, 2005.

[5] AMESim Tutorial Guide.

[6] AMESim User's Guide, Electromechanical Library Rev11.

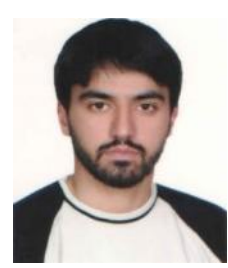

Abdollah Ebadi received his B.Sc. degree in computer hardware engineering in 2011, and his M.Sc. in 2015 from K.N. Toosi University of Technology, Tehran, Iran. Currently he is working in a drilling company in Iran as a researcher. His research interests include mechatronics, vibration suspension and active magnetic bearings. 